\title{
Mitochondrial-Localized Versus Cytosolic Intracellular CO- Releasing Organic PhotoCORMs: Evaluation of CO Effects Using Bioenergetics
}

\author{
Tatiana Soboleva $^{\dagger}$, Hector J. Esquer ${ }^{\ddagger}$, Stacey N. Anderson ${ }^{\dagger}$, Lisa M. Berreau ${ }^{\dagger},{ }^{\star}$, and Abby D. \\ Benninghoff ${ }^{\ddagger},{ }^{*}$ \\ tDepartment of Chemistry and Biochemistry, Utah State University, Logan, Utah 84322-0300, \\ United States \\ ‡Department of Animal, Dairy and Veterinary Sciences, Utah State University, Logan, Utah \\ 84322-4815, United States
}

\begin{abstract}
While interactions between carbon monoxide ( $\mathrm{CO}$ ) and mitochondria have been previously studied, the methods used to deliver $\mathrm{CO}$ (gas or CO-releasing metal carbonyl compounds) lack subcellular targeting and/or controlled delivery. Thus, the effective concentration needed to produce changes in mitochondrial bioenergetics is yet to be fully defined. To evaluate the influence of mitochondrial-targeted versus intracellularly-released $\mathrm{CO}$ on mitochondrial oxygen consumption rates, we developed and characterized flavonol-based $\mathrm{CO}$ donor compounds that differ at their site of release. These molecules are metal-free, visible light triggered CO donors (photoCORMs) that quantitatively release $\mathrm{CO}$ and are trackable in cells via confocal microscopy. Our studies indicate that at a concentration of $10 \mu \mathrm{M}$, the mitochondrial-localized and cytosolic CO-releasing compounds are similarly effective in terms of decreasing ATP production, maximal respiration, and the reserve capacity of A549 cells. This concentration is the lowest to impart changes in mitochondrial bioenergetics for any CO-releasing molecule (CORM) reported to date. The results reported herein demonstrate the feasibility of using a structurally-tunable organic photoCORM framework for comparative intracellular studies of the biological effects of carbon monoxide.
\end{abstract}

\begin{abstract}
Widely known as a toxic gas, carbon monoxide (CO) is now well understood to be a gasotransmitter akin to nitric oxide (NO) and hydrogen sulfide $\left(\mathrm{H}_{2} \mathrm{~S}\right)$. Endogenously produced during heme degradation by heme oxygenase $(\mathrm{HO}), \mathrm{CO}$ has been shown to exert cytoprotective and homeodynamic regulatory functions in a dose-dependent manner. ${ }^{1-5}$
\end{abstract}

\footnotetext{
"Corresponding Author: abby.benninghoff@usu.edu. lisa.berreau@usu.edu. Author Contributions

Experiments were conceived of and designed by TS, HJE, ADB, and LMB. TS and SNA prepared and characterized 2 and 3; TS and HJE performed confocal studies and cytoxicity measurements; TS performed bioenergetics experiments; TS, HJE, LMB and ADB analyzed data and prepared the manuscript.

Supporting Information. NMR, mass spectrometry, UV-vis, and fluorescence data; fluorescence and confocal microscopy images; cytotoxicity and bioenergetics data (PDF). The Supporting Information is available free of charge on ACS Publication website at DOI: 10.1021/acschembio.8b00387
} 
Compared to $\mathrm{NO}$ and $\mathrm{H}_{2} \mathrm{~S}, \mathrm{CO}$ is a relatively inert gas that selectively binds to low-valent transition metal centers. In biological systems, reduced heme proteins, such as those found in hemoglobin, myoglobin, and cytochrome $c$ oxidase (COX, mitochondrial complex IV), are primary CO targets. ${ }^{6-9}$ Two methods of exogenous $\mathrm{CO}$ delivery have been used, thus far, in studies on the effects of $\mathrm{CO}$ on mitochondrial function. These are exposure to $\mathrm{CO}$ gas and delivery of $\mathrm{CO}$ via CO-releasing molecules (CORMs). To date, CORM-2, CORM-3 and CORM-401 (Figure 1) have been used in mitochondrial bioenergetics studies performed using an Extracellular Flux Analyzer. ${ }^{10-13}$ These CORMs are metal carbonyl complexes that spontaneously release $\mathrm{CO}$ via ligand-exchange reactivity. Because these compounds cannot be tracked, it is unclear whether $\mathrm{CO}$ release occurs intracellularly or extracellularly. Therefore, the effective concentration of $\mathrm{CO}$ needed to modulate mitochondrial function remains to be fully defined. In this regard, a current limitation in studies of the effect of $\mathrm{CO}$ on mitochondrial function is the lack of molecular $\mathrm{CO}$ delivery tools that exhibit a specific combination of features. Such molecular tools should be highly controlled for triggered CO delivery, should exhibit fluorescence trackability, and be targetable to mitochondria for localized CO release. Intracellular and/or mitochondrial-localized CO delivery is especially important for investigating the relationship between local concentration of $\mathrm{CO}$ and its biological effects. It is largely accepted that $\mathrm{CO}$ is cytotoxic via its binding to the heme center of COX. ${ }^{14}$ However, low amounts of $\mathrm{CO}$ have also been reported to promote cytoprotection by inducing electron accumulation at complex III resulting in the generation of low amounts of reactive oxygen species (ROS). ${ }^{5,15}$

Organic photoCORMs, metal-free small molecules that can be triggered to release CO using visible-light, offer new approaches to study the effect of $\mathrm{CO}$ on mitochondrial function. We recently reported a flavonol-based photoCORM ${ }^{16}(\mathbf{1}$, Figure 1$)$ that can be tracked intracellularly prior to $\mathrm{CO}$ release via its green fluorescent emission. The base structure of this molecule can easily be modified to impart multifunctional capabilities, such as environment sensing prior to controlled CO release. ${ }^{17,18}$ Herein, we report new derivatives of 1 that contain cationic triphenylphosphonium (TPP) appendages for targeting to mitochondria. These molecules retain the trackability and controlled $\mathrm{CO}$ release of the parent compound. With $\mathbf{1}$ and mitochondrial-specific analogues available, we directed our efforts at examining the influence of intracellular cytosolic versus mitochondria-localized $\mathrm{CO}$ release on cellular toxicity and mitochondrial bioenergetics.

\section{Results and Discussion}

Inspired by the work of Murphy et al. and others ${ }^{19,20}$, we envisioned constructing flavonol analogues of 1 with a cationic triphenylphosphonium (TPP) appendage (Scheme 1). This type of appendage has previously been used in two quercetin derivatives that exhibit mitochondrial localization. ${ }^{21}$ The TPP tail in these molecules was appended on the A ring or at the 3-hydroxy position of the $\mathrm{C}$ ring. These compounds were used as mitochondriotropic prooxidants. We instead chose a synthetic strategy involving functionalization of the B ring (Scheme 1) because of the ease of synthesis and to retain the CO release reactivity of $\mathbf{1}$ from the 3-hydroxy position. Carboxy-appended 1a was prepared using standard Algar-FlynnOyamada reaction conditions. ${ }^{22,23}$ This relatively insoluble flavonol was characterized by elemental analysis, ${ }^{1} \mathrm{H}$ NMR, FTIR, UV-vis, fluorescence and mass spectrometry (Figures 
S1-S5). Addition of either a 2- or 8-carbon linker TPP appendage to 1a was achieved via EDC/HOBt coupling as outlined in Scheme 1 yielding $\mathbf{2}$ and $\mathbf{3}$, respectively. These different alkyl chain lengths were chosen to determine an initial optimal length for cellular uptake and localization studies. ${ }^{24,25}$ Compounds $\mathbf{2}$ and $\mathbf{3}$ are soluble in mixed solvents, such as $\mathrm{CH}_{3} \mathrm{CN}$ :DMSO (10:1), as well as pure ethanol and DMSO at concentrations suitable for spectrophotometric and biological experiments. The appended flavonols were characterized by ${ }^{1} \mathrm{H}$ and ${ }^{31} \mathrm{P}$ NMR, UV-vis, fluorescence and high resolution mass spectrometry (Figures S6-S15). The lowest-energy absorption features of 2 and $\mathbf{3}$ in $\mathrm{CH}_{3} \mathrm{CN}$ :DMSO (10:1) or DMSO are similar to those of $\mathbf{1}^{16}$ with a maximum at $\sim 410 \mathrm{~nm}$. The molar absorptivity values for this lowest-energy band of 1-3 are also similar. Compounds 1-3 are soluble at concentrations up to $100 \mu \mathrm{M}$ in cell culture media supplemented with $10 \%$ fetal bovine serum (FBS) and are stable for at least one month if protected from light. In cell culture media, each compound exhibits a flavonol anion absorption band centered at $\sim 480 \mathrm{~nm}^{26}$ indicating deprotonation of the 3-hydroxy moiety in at least a portion of the sample. Notably, the degree of anion formation is enhanced in compounds containing the cationic phosphonium tail (Figure 2(a)) as indicated by higher absorption intensity at $\sim 480 \mathrm{~nm}$.

Excitation of 1-3 at $\sim 410 \mathrm{~nm}$ in cell culture media produces two emission bands centered at $\sim 480 \mathrm{~nm}$ and $\sim 600-610 \mathrm{~nm}$, respectively. These bands correspond to the excited state normal ( $\mathrm{N}^{*}$ ) and tautomeric ( $\mathrm{T}^{*}$ ) forms of the neutral flavonol (Figure 2(b)). ${ }^{26}$ Excitation into the anion absorption band at $\sim 480 \mathrm{~nm}$ produces a single broad emission centered at 554 $\mathrm{nm}$ for $\mathbf{1}$ and slightly red-shifted ( $\sim 8 \mathrm{~nm}$ ) for $\mathbf{2}$ and $\mathbf{3}$ (Figure 2(c)). For cell imaging, conditions under which the most intense emission features for 1-3 are produced are desired. As outlined in Figure 2(c), excitation in the anion absorption band $\left(\lambda_{\mathrm{ex}}=480 \mathrm{~nm}\right)$ produces an emission feature that is largely localized in the green detection channel (495-582 nm) used for confocal studies. Comparatively, excitation in the $410 \mathrm{~nm}$ band produces an emission that is shifted significantly out of the range of the green detection channel. Comparing the two TPP-tailed derivatives, 2 exhibits a higher emission intensity in the green channel when excited at $480 \mathrm{~nm}$, which suggested that it would be a better candidate for intracellular mitochondrial visualization studies. Importantly, the excitation and emission features of 1-3 do not interfere with those of the co-staining dyes Hoechst 33342 and MitoTracker Red CMXRos (Figure 2(c)) that are used in cellular imaging of mitochondrial localization (vide infra).

The visible light-induced CO-releasing properties of $\mathbf{2}$ and $\mathbf{3}$ were compared to those of $\mathbf{1}$. Exposure of aerobic solutions of $\mathbf{2}$ and $\mathbf{3}$ to visible light $(419 \mathrm{~nm})$ resulted in the loss of emission and absorption features (Figure S16 and S17) and quantitative CO release (2: 1.0(3) equiv.; 3: 0.98(2) equiv.) as determined by gas chromatography headspace analyses. The quantum yield for the CO release reactions of $\mathbf{2}$ and $\mathbf{3}$ is $0.007(1)$, which is identical to that of $\mathbf{1}(0.007(3)) .{ }^{26}$ Control reactions indicated that both $\mathrm{O}_{2}$ and visible light were required for the $\mathrm{CO}$ release reactivity of $\mathbf{2}$ and $\mathbf{3}$, which is similar to $\mathbf{1}$. It should be noted that we have previously shown that the parent compound $\mathbf{1}$ exhibits quantitative CO-release reactivity even under hypoxic conditions $\left(1 \% \mathrm{O}_{2}\right) \cdot{ }^{17}$ The organic products resulting from $\mathrm{CO}$ release from $\mathbf{2}$ and $\mathbf{3}$ (4 and $\mathbf{5}$, respectively, Scheme 1) were characterized by ${ }^{1} \mathrm{H}$ NMR and high resolution mass spectrometry (Figures S18-21). While the ${ }^{1} \mathrm{H}$ NMR features and 
the molecular ion for $\mathbf{5}$ are consistent with the proposed formulation of the depside (Scheme 1), the CO release product $\mathbf{4}$ could not be identified intact by ESI/APCI-MS. Rather, the mass spectrometry results indicated hydrolytic cleavage of the ester moiety following $\mathrm{CO}$ release.

An initial qualitative comparison of the cellular uptake of $\mathbf{1}$ and $\mathbf{2}$ was performed in adenocarcinoma human alveolar basal epithelial cells (A549 cells) using standard 10× (1 and $\mathbf{2}$ ) and 20x ( $\mathbf{1}$ only) fluorescence microscopy (Figure S22). Both compounds are visible intracellularly via a strong green emission. Switching to confocal microscopy at $63 \times$ magnification, qualitative fluorescent signal intensity differences were noted (Figures S23S25). In A549 cells, no green emission could be detected for $\mathbf{1}$ introduced at $100 \mu \mathrm{M}$, whereas $\mathbf{2}$ and $\mathbf{3}$ at the same concentration were readily visible. In the noncancerous human umbilical vein cell line (HUVECs), a faint green emission is seen for $\mathbf{1}$ using confocal microscopy, and $\mathbf{2}$ exhibits a more intense emission than $\mathbf{3}$. A possible reason for why $\mathbf{1}$ is difficult to visualize using confocal microscopy is the stronger and more focused light source, which may induce this cytosolic compound ${ }^{16}$ to undergo light-driven $\mathrm{CO}$ release to give the non-emissive depside product. Our ability to easily visualize $\mathbf{2}$ and $\mathbf{3}$ using confocal microscopy suggests differences in localization as compared to $\mathbf{1}$. Of the tailed compounds, 2 exhibits the more robust emissive features in both cell lines (Figure S23). The optimal concentration of 2 for intracellular visualization ( 75 or $100 \mu \mathrm{M}$ after $4 \mathrm{~h}$ of cellular exposure) was determined from a concentration-dependent experiment (Figure S23(c)).

To assess localization, we compared the intracellular fluorescent emission of $\mathbf{2}$ and $\mathbf{3}$ to that of MitoTracker Red CMXRos (MTR), which is known to localize in the mitochondria. ${ }^{27}$ Incubation of A549 cells with 2 at $100 \mu \mathrm{M}$ for $4 \mathrm{~h}$ showed that the compound localizes similarly to the MTR dye as indicated by the yellow-orange color in the merged image (Figure 3). Similar co-localization results for 2 were observed in HUVECs, albeit with a lower emission intensity (Figure S26). Similar studies performed using $\mathbf{3}$ in both cell lines showed co-localization with MTR but with fainter signal intensity as compared to $\mathbf{2}$ (Figures S27 and S28). This set of experiments suggested that further biological testing would be optimal using A549 cells and compound 2.

The overlap between $\mathbf{2}$ and MTR in A549 cells was determined to be substantial as evidenced by the Pearson's co-localization coefficient, $r=0.707 \pm 0.014$ (mean \pm SEM for 29 cells examined individually) (Figure 4(a)). This approach was taken to avoid false positive co-localization pixels from background noise, channel bleeding and zero-zero background pixel co-localization. Regions of interest and their spatial resolution were evaluated as a line profile over a distance of 30 microns (Figure 4(b)). The congruence of the intensity profiles of $\mathbf{2}$ and MTR strongly suggest that $\mathbf{2}$ is localizing in mitochondria.

As noted above, $\mathbf{1}$ is readily bleached upon exposure to the confocal microscopy laser light source. Based on the higher local concentration of $\mathbf{2}$ at mitochondria, we anticipated that this compound might require additional light-exposure to trigger $\mathrm{CO}$ release. To test this idea, A549 cells incubated with $2(25 \mu \mathrm{M})$ were exposed to $488 \mathrm{~nm}$ laser illumination (11.5 $\mathrm{mW} / \mathrm{cm}^{2}$ at $6 \%$ laser power) for 5 minutes (Figure S29). The loss of green fluorescence emission from 2 over this time period indicates intracellular light-triggered CO release. ${ }^{16}$ 
While this bleaching is direct evidence of $\mathrm{CO}$ release, we also note that we have previously demonstrated intracellular CO production from 1 using a Nile red-based $\mathrm{CO}$ sensor. ${ }^{18}$

MTT assays were used to compare the cytotoxicity of cytosolic $\mathbf{1}$ and the mitochondrialocalized $\mathbf{2}$ and $\mathbf{3}$ in both HUVECs and A549 cells. As reported previously, $\mathbf{1}$ was found to be mildly toxic to A549 cells, with an average $\mathrm{IC}_{50}$ value of $80.2 \pm 3.3 \mu \mathrm{M}^{16}$ (Table S1; Figure S30). Compounds $\mathbf{2}$ and $\mathbf{3}$ are more cytotoxic, with mean $\mathrm{IC}_{50}$ values of $14.1 \pm 2.7$ and 8.48 $\pm 4.0 \mu \mathrm{M}$, respectively (Table S1; Figure S30). In HUVECs, 1 showed no cytotoxicity up to $50 \mu \mathrm{M}$. In contrast, 2 and $\mathbf{3}$ decreased cell viability with $\mathrm{IC}_{50}$ values of $1.51 \pm 1.4 \mu \mathrm{M}$ and 8.40 $\pm 3.6 \mu \mathrm{M}$, respectively (Table S1; Figure S31).

The organic product (depside) derived from the CO release reaction of $\mathbf{1}$ in A549 cells has been previously reported to be nontoxic up to $100 \mu \mathrm{M} .{ }^{16}$ Compound 4 , which results from the $\mathrm{CO}$ release reaction of $\mathbf{2}$, is nontoxic in A549 cells up to $100 \mu \mathrm{M}$ (Figure S30). However, 5 is moderately toxic with an $\mathrm{IC}_{50}$ value of $69.1 \pm 11 \mu \mathrm{M}$. Similarly, in HUVECs, while 4 showed no cytotoxicity, $\mathbf{5}$ is mildly cytotoxic with an $\mathrm{IC}_{50}$ of $90.0 \pm 7.5 \mu \mathrm{M}$. To assess the cytotoxicity of just the TPP appendage, 2-carboxyethyl-triphenylphosphonium bromide (TPPBr) was evaluated using an MTT assay. In both cell lines, this compound was determined to be nontoxic up to $100 \mu \mathrm{M}$. Thus, it is the combination of the flavonol scaffold in $\mathbf{2}$ and $\mathbf{3}$ with the TPP appendage that leads to enhanced cytotoxicity. The lower cytotoxicity of 2 and its $\mathrm{CO}$ release product 4 relative to the $\mathbf{3 / 5}$ combination indicated that the shorter tailed compound was more suitable for subsequent mitochondrial studies, especially in A549 cells. Compound 2 also had good cellular uptake as indicated by the confocal microscopy studies.

We next evaluated the cytotoxicity profile of the cytosolic $\mathbf{1}$ and the mitochondrial-localized 2 under illumination conditions in both cell lines (Figure 5). This strategy was devised to gain insight into the effect of localized versus cytosolic triggered $\mathrm{CO}$ release on cellular viability. In A549 cells, illumination of $\mathbf{1}$ resulted in very little change in the $\mathrm{IC}_{50}$ value (1: $\left.\mathrm{IC}_{50}=76.1 \pm 5.2 \mu \mathrm{M}\right)$, however a decrease was observed for $\mathbf{2}\left(\mathrm{IC}_{50}=4.6 \pm 3.6 \mu \mathrm{M}\right.$; Figure 5) as compared to the non-illuminated sample. In HUVECs, 2 showed significant cytotoxicity $\left(\mathrm{IC}_{50}=3.78 \pm 1.5 \mu \mathrm{M}\right.$; Table S2; Figure S32), whereas 1 was nontoxic up to $100 \mu \mathrm{M}$. Under illumination conditions, the CO release products of $\mathbf{1}$ and $\mathbf{2}$ as well as the TPP tail were found to be nontoxic up to $100 \mu \mathrm{M}$ (Figure S32).

To gain insight into the enhanced cytotoxicity observed upon in situ CO release, we evaluated the mitochondrial bioenergetics of intact A549 cells treated with $\mathbf{1}$ or $\mathbf{2}$ at the concentration range of $0.1-10 \mu \mathrm{M}$ using an Extracellular Flux Analyzer (vide infra). ${ }^{28}$ Using this technique, we measured six key parameters of mitochondrial function in real-time upon exposure to CO delivered by $\mathbf{1}$ or $\mathbf{2}$. The addition of the oxidative phosphorylation inhibitors oligomycin (an ATP synthase inhibitor), carbonyl cyanide-4-

(trifluoromethoxy)phenylhydrazone (a mitochondrial uncoupler), and a combination of antimycin A and rotenone (complex III and complex I inhibitors, respectively) allowed for a detailed analysis of the bioenergetics profile and the specific functions of the mitochondria that were affected by $\mathrm{CO}$ release from the cytosolic versus mitochondrial-localized compounds. As shown in Figure 6, four bioenergetics parameters, basal respiration, ATP 
production, maximal respiration and reserve capacity, were decreased upon $\mathrm{CO}$ release from both 1 and 2 at $10 \mu \mathrm{M}$ after $1 \mathrm{~h}$ of illumination to induce $\mathrm{CO}$ release. The decrease in basal respiration contrasts with an increase in the same parameter identified in studies using metal carbonyl CO-release compounds (Figure S33 and Figure S34). ${ }^{10-13}$ Variances in cellular uptake, localization and/or triggered versus solution-driven $\mathrm{CO}$ release for $\mathbf{1}$ and $\mathbf{2}$ may produce the differing effects of $\mathrm{CO}$ on OCR (oxygen consumption rate) parameters as compared to the metal carbonyl CORMs (CORM-401, CORM-2, and CORM-3). In this regard, it is important to note that the concentration $(10 \mu \mathrm{M})$ needed for $\mathbf{1}$ or $\mathbf{2}$ to produce significant changes in these bioenergetics parameters is at least two-fold lower than all previously tested CORMs (Figure S34). ${ }^{10-13}$ The intracellular localization and triggered CO release of the flavonol-based photoCORMs likely facilitated effective CO delivery. Most importantly, the observed results for $\mathbf{1}$ and $\mathbf{2}$ at $10 \mu \mathrm{M}$ are highly similar, indicating that mitochondrial-localized versus cytosolic $\mathrm{CO}$ release did not result in marked differences in the bioenergetics responses. As this initial study focused on a 1000-fold range of concentrations for $\mathbf{1}$ and $\mathbf{2}(0.1-10 \mu \mathrm{M})$, and no significant effects were observed at $1 \mu \mathrm{M}$ or below, future studies involving these compounds will need to focus on examining OCR parameters in the range of $1-10 \mu \mathrm{M}$.

We note that at the lowest concentration of $1(0.1 \mu \mathrm{M})$, a decrease in the bioenergetics parameters was observed under both illumination and non-illumination conditions (Figure 6 and Figure S33). This effect was likely due to the flavonol scaffold and not CO release. It is known that flavonols such as quercetin ${ }^{29-31}$ and baicalein ${ }^{32}$ can produce differing effects on mitochondrial bioenergetics. Whereas baicalein decreases ATP-production via uncoupling of mitochondrial membranes, ${ }^{32}$ quercetin increases basal respiration, maximal respiration, ATP-linked respiration and the reserve capacity of mitochondria. ${ }^{29-31}$

We carefully considered appropriate controls for the mitochondrial bioenergetics experiments. In some prior bioenergetics studies involving metal carbonyl-type CORMs (Figure S34; CORM-401 and CORM-3), the CO-release product, termed an iCORM (inactivated CORM), was examined as a control. ${ }^{10-12}$ This was done as an approach to provide evidence that it was $\mathrm{CO}$, and not the $\mathrm{iCORM}$, that was responsible for the observed effects. It is important to note that a true iCORM for CORM-401 cannot be prepared and that only uncharacterized mixtures of the supporting ligand and $\mathrm{MnSO}_{4}$ have been used as a control. ${ }^{12,33}$ The iCORM for CORM-3 is a minimally characterized cis-[Ru(CO) $\left.)_{2}\right]^{2+}$ species that has been questioned as an appropriate control. ${ }^{34}$ It is unclear whether these metalcontaining iCORMs would have the same cellular uptake and/or distribution as the CORMs themselves. For $\mathbf{1}$ and $\mathbf{2}$, the CO-release products are well-characterized and contain a carboxylic acid moiety. At physiological $\mathrm{pH}$, this functional group will be ionized, which is likely to reduce cellular uptake relative to the neutral $\mathbf{1}$ and $2 .{ }^{35}$ As both $\mathbf{4}$ and the CO release product of $\mathbf{1}$ are also non-fluorescent, their cellular uptake would be difficult to evaluate. For these reasons, we did not believe that $\mathbf{4}$ and the $\mathrm{CO}$ release product of $\mathbf{1}$ would be appropriate controls. We instead chose to use a model of the phosophonium tail (TPPBr; $0.1-10 \mu \mathrm{M}$, Figure 6 and Figure S33) as it has the highest likelihood of producing mitochondrial-specific effects. Notably, no significant changes in the mitochondrial bioenergetics profile in either illuminated or non-illuminated cells were observed in the 
presence of TPPBr. Overall, the observed decreases in ATP production, maximal respiration and reserve capacity upon $\mathrm{CO}$ release from $\mathbf{1}$ and $\mathbf{4}$ and metal carbonyl derivatives (Figure S34) suggest that a common entity, carbon monoxide, is responsible.

We note that while this manuscript was under review a contribution containing a metal-free mitochondrial-targeting, spontaneous CO-releasing molecule was published, albeit with no evaluation of the effect of $\mathrm{CO}$ on mitochondrial function. ${ }^{36}$ The results presented herein are the first application of the use of any non-metal CORM, including organic photoCORMs ${ }^{37-39}$, to assess the influence of $\mathrm{CO}$ on mitochondrial function.

\section{Conclusions}

The results reported herein mark several important advancements in the use of CORMs for analyzing the biological effects of $\mathrm{CO}$. First, the use of an easily functionalized organic framework enabled the introduction of a targeting motif without modification of key spectroscopic properties (e.g., fluorescence emission) or the $\mathrm{CO}$ release reactivity of the delivery compound. Importantly, the flavonol-based cytosolic and mitochondrial-targeted photoCORMs enable comparative tracking for cellular uptake and localization, which has not been previously achieved with CORMs that have been used in probing the effects of $\mathrm{CO}$ on mitochondrial function. In this regard, this study provides the first examples of structurally-related, triggered $\mathrm{CO}$ donors that can be used to evaluate the importance of localization of $\mathrm{CO}$ release on cellular toxicity and respiration. The initial bioenergetics results reported herein suggest that intracellular, non-localized CO release is similarly effective as mitochondrial-localized $\mathrm{CO}$ delivery for modulating cellular bioenergetics parameters. The fact that a lower concentration of an intracellular photoCORM can be used to produce similar effects to those previously identified for metal carbonyl CORMs in bioenergetics studies indicates that cellular uptake and highly controlled $\mathrm{CO}$ release play a key role in effective $\mathrm{CO}$ delivery.

\section{Materials and Methods}

\section{Chemicals and Reagents}

All chemicals and reagents were obtained from commercial sources and used as received unless otherwise noted.

\section{Physical Methods}

${ }^{1} \mathrm{H}$ and ${ }^{31} \mathrm{P}\left\{{ }^{1} \mathrm{H}\right\}$ NMR spectra were collected using a JEOL ECX-300 and Brüker AvanceIII HD Ascend-500 spectrometers and are referenced to the residual solvent peak in $\mathrm{CDCl}_{3}\left({ }^{1} \mathrm{H}\right.$ : 7.26 (singlet) ppm), $\mathrm{D}_{2} \mathrm{O}\left({ }^{1} \mathrm{H}: 4.80\right.$ (br. singlet) ppm), DMSO- $d_{6}\left({ }^{1} \mathrm{H}: 2.50\right.$ (multiplet) ppm), and $\mathrm{CD}_{3} \mathrm{OD}\left({ }^{1} \mathrm{H}: 4.78\right.$ (singlet) ppm). $J$ values are given in $\mathrm{Hz}$. Infrared spectra were recorded as potassium bromide pellets using a Shimadzu FTIR-8400 (Kyoto, Japan). UV-vis spectra were recorded at ambient temperature using a Hewlett-Packard 8453A diode array or a CARY 50Bio spectrophotometer. Fluorescence emission spectra were collected using a Shimadzu RF-530XPC spectrometer in the range of 400-800 nm, with the excitation wavelength corresponding to the absorption maximum of the analyzed molecule in the solvent of choice. The excitation and emission slit widths were set at $1.5 \mathrm{~nm}$ for all emission 
measurements. Mass spectral data were collected at the Mass Spectrometry Facility, University of California, Riverside. A Rayonet photoreactor equipped with RPR-4190A lamps (2,450 lx, light intensity) was used for all non-cellular photochemical reactions. Illumination of cells prior to cytotoxicity assays and bioenergetics studies were performed using a blue LED array $(66,351 \mathrm{~lx}$, light intensity).Carbon monoxide was quantified as previously described. ${ }^{40}$ Quantum yields were determined using potassium ferrioxalate as a standard to measure photon flux..$^{41,42}$.

\section{Synthetic methods}

(2-aminoethyl)triphenyl phosphonium bromide (1:1), 8-bromo-1-hexanol, 8-amino-1octanol, 2-(8-hydroxyoctyl)-1H-isoindole-1,3(2H)-dione, and 8-bromo-octamine hydrobromide (1:1) were synthesized according to the literature procedures. ${ }^{43-46}$

\section{Synthesis of (2-(4-(3-hydroxy-4-oxo-4H-benzo[g]chromen-2- yl)benzamido)ethyl)triphenylphosphonium bromide (2) or (8-(4-(3-hydroxy-4- oxo-4H-benzo[g]chromen-2-yl)benzamido)octyl)triphenylphosphonium} bromide (3)-3-hydroxy-2-(4-carboxy)phenyl-benzo[g]chromen-4-one (1a) (0.861g, 2.59 mmol), $N$-(3-dimethylaminopropyl)- $N$-ethylcarbodiimide hydrochloride (EDC.HCl) $(0.596$ $\mathrm{g}, 3.11 \mathrm{mmol})$, and 1-hydroxybenzotriazole hydrate (HOBt) $(0.476 \mathrm{~g}, 3.11 \mathrm{mmol})$ were combined in $40 \mathrm{~mL}$ DMF and stirred for 2 hours protected from light. The appropriate triphenylphosphonium bromide salt $(2.59 \mathrm{mmol})$ was dissolved in $40 \mathrm{~mL}$ of DMF and added to the reaction mixture, which was then stirred for 24 hours at room temperature. The solvent was then removed under vacuum and the remaining solid was dissolved in dichloromethane and washed with water $(3 \times 60 \mathrm{~mL})$. The combined organic fractions were dried over $\mathrm{Na}_{2} \mathrm{SO}_{4}$, filtered and concentrated under reduced pressure. In each case, the resulting solid was washed with ethyl acetate and diethyl ether to obtain pale-orange solid (60\% yield). Compound 2: ${ }^{1} \mathrm{H}$ NMR (DMSO- $\left.d_{6}, 500 \mathrm{MHz}\right) \delta 9.09(\mathrm{~s}, 1 \mathrm{H}), 8.87(\mathrm{~s}, 1 \mathrm{H})$, $8.38(\mathrm{~d}, J=8.5 \mathrm{~Hz}, 2 \mathrm{H}), 8.35(\mathrm{~s}, 1 \mathrm{H}), 8.27(\mathrm{~d}, J=8.9 \mathrm{~Hz}, 1 \mathrm{H}), 8.09(\mathrm{~d}, J=8.89 \mathrm{~Hz}, 1 \mathrm{H})$, 7.95-7.67 (m, 15H), 7.62-7.56 (m, 1H), $7.51(\mathrm{~d}, J=8.9 \mathrm{~Hz}, 2 \mathrm{H}), 7.27(\mathrm{t}, J=8.3 \mathrm{~Hz}, 1 \mathrm{H})$, $7.23(\mathrm{t}, J=8.3 \mathrm{~Hz}, 1 \mathrm{H}), 3.94-3.82(\mathrm{~m}, 2 \mathrm{H}), 3.54-3.52(\mathrm{~m}, 2 \mathrm{H})$, ppm. ${ }^{31} \mathrm{P}\left\{{ }^{1} \mathrm{H}\right\}$ (DMSO- $d_{6}$, $202 \mathrm{MHz}) \delta$ 20.77. UV-vis $\left(\mathrm{CH}_{3} \mathrm{CN}: \mathrm{DMSO}(10: 1), \mathrm{nm}\right)\left(\varepsilon, \mathrm{M}^{-1} \mathrm{~cm}^{-1}\right) 414(9.48 \pm 0.1 \times$ $\left.10^{3}\right), 394\left(9.50 \pm 0.1 \times 10^{3}\right), 347\left(16.5 \pm 0.2 \times 10^{3}\right)$. ESI/APCI-MS (relative intensity) calcd. for $\mathrm{C}_{40} \mathrm{H}_{31} \mathrm{NO}_{4} \mathrm{P}[\mathrm{M}]^{+}: 620.1991$; found: 620.1999 (100\%).

Compound 3: ${ }^{1} \mathrm{H}$ NMR (DMSO- $\left.d_{6}, 300 \mathrm{MHz}\right) \delta 8.87$ (s, 1H), 8.61 (s, $1 \mathrm{H}$ ), 8.37 (d, $J=8.9$ $\mathrm{Hz}, 2 \mathrm{H}), 8.34$ (s, 1H), 8.27 (d, $J=8.5 \mathrm{~Hz} 1 \mathrm{H}), 8.09$ (d, $J=8.5 \mathrm{~Hz}, 1 \mathrm{H}), 8.02(\mathrm{~d}, J=8.9 \mathrm{~Hz}$, $2 \mathrm{H}), 7.94-7.67(\mathrm{~m}, 15 \mathrm{H}), 7.59$ (t, $J=8.0 \mathrm{~Hz}, 1 \mathrm{H}), 7.48-7.44(\mathrm{~m}, 1 \mathrm{H}), 7.34(\mathrm{t}, J=8.0 \mathrm{~Hz}, 1 \mathrm{H})$ 3.60-3.43 (m, 2H), 1.50-1.30 (m, 7H), 1.28-1.17 (m, 5H) ppm. ${ }^{31} \mathrm{P}\left\{{ }^{1} \mathrm{H}\right\}$ NMR (DMSO- $d_{6}$, $202 \mathrm{MHz}) 20.74 \mathrm{ppm}$. UV-vis $\left(\mathrm{CH}_{3} \mathrm{CN}\right.$ :DMSO $\left.(10: 1), \mathrm{nm}\right)\left(\varepsilon, \mathrm{M}^{-1} \mathrm{~cm}^{-1}\right) 414(7.26 \pm 0.1 \times$ $\left.10^{3}\right), 394\left(7.38 \pm 0.1 \times 10^{3}\right), 347\left(11.5 \pm 0.2 \times 10^{3}\right)$. ESI/APCI-MS (relative intensity) calcd. for $\mathrm{C}_{46} \mathrm{H}_{43} \mathrm{NO}_{4} \mathrm{P}[\mathrm{M}]^{+}$: 704.2930; found: $704.3382(100 \%)$.

Photoreactivity of 2 and 3-A solution of 2 or $\mathbf{3}(\sim 0.05 \mathrm{mmol})$ in $5.0 \mathrm{~mL}$ DMSO was placed in a $50 \mathrm{~mL}$ round bottom flask under air. The flask was then placed in a Rayonet photoreactor equipped with $419 \mathrm{~nm}$ lamps (light intensity 2,450 lx) and illuminated until the 
reaction was determined complete ( $24 \mathrm{~h})$ as evidenced by the loss of the lowest energy absorption band of each compound at $410 \mathrm{~nm}$. The solvent was then removed via lyophilization yielding $\mathbf{4}$ and $\mathbf{5}$.

(2-(4-)((3-carboxynaphthalen-2yl)oxy)carbonyl)benzamido)ethyl)triphenylphosphonium bromide (4)- ${ }^{1} \mathrm{H}$ NMR (DMSO- $\left.d_{6}, 500 \mathrm{~Hz}\right) \delta 9.01(\mathrm{~s}, 1 \mathrm{H}), 8.27(\mathrm{~s}, 1 \mathrm{H}), 8.01(\mathrm{~d}, J=8.0 \mathrm{~Hz}, 1 \mathrm{H}), 7.95-7.68(\mathrm{~m}$, $15 \mathrm{H}), 7.63(\mathrm{~d}, J=8.2 \mathrm{~Hz}, 2 \mathrm{H}), 7.57(\mathrm{~d}, J=7.9 \mathrm{~Hz}, 1 \mathrm{H}), 7.46-7.42(\mathrm{~m}, 2 \mathrm{H}), 7.37-7.34(\mathrm{~m}$, $3 \mathrm{H}), 6.93(\mathrm{~s}, 1 \mathrm{H}), 3.94-3.82(\mathrm{~m}, 2 \mathrm{H}), 3.54-3.52(\mathrm{~m}, 2 \mathrm{H}), \mathrm{ppm}$. ESI/APCI-MS (relative intensity) calcd. for $\mathrm{C}_{39} \mathrm{H}_{31} \mathrm{NO}_{5} \mathrm{P}[\mathrm{M}]^{+}: 624.6409$; found $[\mathrm{M}]^{+}:$454.1504. The identified peak corresponds to the hydrolyzed triphenylphosphonium-containing appendage resulting from ester hydrolysis in $\mathbf{4}$.

(8-(4-)((3-carboxynaphthalen-2yl)oxy)carbonyl)benzamido)octyl)triphenylphosphonium bromide (5)— ${ }^{1} \mathrm{H}$ NMR $\left(\right.$ DMSO$\left.d_{6}, 500 \mathrm{~Hz}\right) \delta 8.69(\mathrm{~s}, 1 \mathrm{H}), 8.23(\mathrm{~d}, J=8.9 \mathrm{~Hz}, 2 \mathrm{H}), 8.18(\mathrm{~d}, J=8.5 \mathrm{~Hz}, 1 \mathrm{H}), 8.12$ $(\mathrm{d}, J=8.9 \mathrm{~Hz}, 2 \mathrm{H}), 8.01-7.98(\mathrm{~m}, 2 \mathrm{H}), 7.94-7.70(\mathrm{~m}, 15 \mathrm{H}), 7.66-7.62(\mathrm{~m}, 2 \mathrm{H}), 7.55(\mathrm{t}, J=$ $8.0 \mathrm{~Hz}, 1 \mathrm{H}), 7.42(\mathrm{t}, J=7.9 \mathrm{~Hz}, 1 \mathrm{H}), 3.60-3.43(\mathrm{~m}, 2 \mathrm{H}), 1.50-1.30(\mathrm{~m}, 7 \mathrm{H}), 1.28-1.17$ (m, $5 \mathrm{H}) \mathrm{ppm}$. ESI/APCI-MS (relative intensity) calcd. for $\mathrm{C}_{45} \mathrm{H}_{43} \mathrm{NO}_{5} \mathrm{P}[\mathrm{M}]^{+}: 708.2879$; found: $708.3001(100 \%)$.

\section{Cell culture growth parameters}

Human lung adenocarcinoma human alveolar basal epithelial cells (A549 cells) were obtained from ATCC (Manassas, VA) and cultured in phenol-red free DMEM-F12K Media (Caisson Laboratories, Smithfield, UT) supplemented with 10\% (v/v) FBS. These A549 cells were fed every 3 days with fresh media and sub-cultured in T-75 flasks at 4,000 cells $/ \mathrm{cm}^{2}$. Cells were detached by addition of $3 \mathrm{~mL}$ of Trypsin-EDTA $1 \times$ solution (Caisson Laboratories) for $5 \mathrm{~min}$, then neutralized with $8 \mathrm{~mL}$ of fresh media. A549 cells were counted using a Cell Countess instrument (ThermoFisher, Boston, MA) according to the manufacturer's protocol. Only passages $1-8$ were used in experiments. Human umbilical vein endothelial cells (HUVECs) were obtained from ATCC (Manassas, VA) and cultured in F-12K Medium (Gibco, Carlsbad, CA) supplemented with $0.03 \mathrm{mg} / \mathrm{ml}$ endothelial cell growth (Sigma-Aldrich, St. Louis, MO), 10\% fetal bovine serum (FBS) (Caisson Laboratories), $0.1 \mathrm{mg} / \mathrm{ml}$ heparin (Sigma-Aldrich) and $100 \mathrm{U} / \mathrm{ml}$ streptomycin-penicillin solution (Gibco). Cell growth, sub-culturing and counting were performed in the same manner as for A549 cells.

\section{Qualitative intracellular visualization of 1 and 2 in cells using fluorescence microscopy}

Initial assessment of the cellular uptake properties of $\mathbf{1}$ and $\mathbf{2}$ was performed using A549 cells monitored via fluorescence microscopy. The cells were maintained in culture as described above, then seeded into Millicell E-Z-Slide chambers (EMD Millipore, Billerica, MA) at a density of 100,000 cells $/ \mathrm{cm}^{3}$ and allowed to adhere for $24 \mathrm{~h}$. Under minimal red light, the cells were treated with $100 \mu \mathrm{M} 1$ or 2 for $4 \mathrm{~h}$, and then washed three times with culture media to remove residual compound. Cell nuclei were stained with Hoechst 33342 (Immunochemistry Technologies, LLC, Bloomington, MN) at $0.5 \% \mathrm{v} / \mathrm{v}$ for 15 minutes. Cell 
imaging was performed using a Zeiss Axio Observer inverted microscope (Carl Zeiss Microscopy, Thornwood, NY) equipped with fluorescence detection. Images were acquired at $10 \times$ and $20 \times$ magnification with the following excitation and emission parameters: for 1 or 2 (green channel), $\lambda_{\mathrm{ex}}=450-490 \mathrm{~nm}, \lambda_{\mathrm{em}}=500-550 \mathrm{~nm}$; for Hoechst (blue channel), $\lambda_{\mathrm{ex}}=310-390 \mathrm{~nm}, \lambda_{\mathrm{em}}=420-470 \mathrm{~nm}$. The acquired images were universally adjusted using ZEISS ZEN Lite software v2.3.

\section{Initial confocal imaging of 1-3 in live cells}

A549 cells or HUVECs were seeded at 100,000 cells $/ \mathrm{cm}^{3}$ in 4-well Millicell@ E-Z Slides (Millipore) for $24 \mathrm{~h}$ of adherence. Then, $100 \mu \mathrm{M}$ of 1-3 in DMSO were added for an additional $4 \mathrm{~h}$. The cells were co-stained with Hoechst ( $0.5 \% \mathrm{v} / \mathrm{v})$ for 15 minutes. Residual compound was washed out twice with fresh media. The cells were imaged using a Zeiss LSM 710 confocal microscope (Thornwood, NY) using the following excitation lasers and emission ranges: 1-3 $\lambda_{\mathrm{ex}}=488 \mathrm{~nm}, \lambda_{\mathrm{em}}=495-582 \mathrm{~nm}$; Hoechst 33342 stain, $\lambda_{\mathrm{ex}}=405$ $\mathrm{nm}, \lambda_{\mathrm{em}}=410-492 \mathrm{~nm}$. The acquired images were universally adjusted using ZEISS ZEN Lite software v2.3.

\section{Co-localization studies of 2 and 3 using MitoTracker Red in A549 cells and HUVECs}

A549 cells or HUVECs were seeded at $100,000 \mathrm{cells} / \mathrm{cm}^{3}$ in 4-well Millicell@ E-Z Slides (Millipore) for $24 \mathrm{~h}$ for adherence. Then, $25-100 \mu \mathrm{M}$ of $\mathbf{2}$ or $\mathbf{3}$ in DMSO were added for an additional $4 \mathrm{~h}$. Hoechst ( $0.5 \% \mathrm{v} / \mathrm{v})$ and MitoTracker Red CMXRos (MTR) (ThermoFisher) at $300 \mathrm{nM}$ were then added for 15 minutes. Residual stains were washed out twice with fresh media. The cells were imaged using a Zeiss LSM 710 confocal microscope using the following excitation lasers and emission ranges: $1-3 \lambda_{\mathrm{ex}}=488 \mathrm{~nm}, \lambda_{\mathrm{em}}=495-582 \mathrm{~nm}$; Hoechst 33342 stain, $\lambda_{\mathrm{ex}}=405 \mathrm{~nm}, \lambda_{\mathrm{em}}=410-492 \mathrm{~nm}$; MTR, $\lambda_{\mathrm{ex}}=561 \mathrm{~nm}, \lambda_{\mathrm{em}}=579$ $600 \mathrm{~nm}$. The acquired images were universally adjusted using ZEISS ZEN Lite software v2.3.

\section{Pearson's coefficient determination for 2 co-localized with MitroTracker in A549 cells}

The coloc2 plugin (open-source Fiji ImageJ 1.51t) was used to determine co-localization of 2 with MTR in A549 cells using background-subtracted (50 pixel radius) confocal image pairs with the Costes threshold regression method. Each cell was isolated as a region of interest to avoid skewing the correlation by the low intensity background pixels. Pearson $r$ correlation values were obtained for 29 cells from six separate fields of view obtained from two independent experiments. A map of co-localized pixels for a representative field of view was also generated and colorized by fluorescence emission intensity. Also, co-localization of 2 with MTR was verified for a subset of cells by plotting light intensity for emission channels for 2 (green), MTR (red) and the Hoechst 33342 nuclear stain (blue) along a linear cross section of the cell.

\section{Illumination of 2 for CO release in A549 cells during confocal imaging}

A549 cells were seeded at 25,000 cells $/ \mathrm{cm}^{3}$ in $35 \mathrm{~mm}$ glass bottom dishes (MatTek, Ashland, MA) for $24 \mathrm{~h}$. The cells were then treated with $2(25 \mu \mathrm{M})$ for an additional $4 \mathrm{~h}$ protected from light. After co-staining for 15 min with Hoechst, the cells were washed three 
times with fresh media to remove excess dye. The cells were imaged using a Zeiss LSM 710 confocal microscope as outlined above. To induce $\mathrm{CO}$ release, the cells were exposed to laser illumination for 5 minutes using either a $405 \mathrm{~nm}$ laser or a combination of 405 and 488 $\mathrm{nm}$ lasers $\left(11.5 \mathrm{~mW} / \mathrm{cm}^{2}\right.$ at $6 \%$ laser power). This resulted in the disappearance of the green emission of $\mathbf{2}$ indicating $\mathrm{CO}$ release and the formation of $\mathbf{4}$.

\section{MTT assays}

Three independent biological experiments, each with three technical replicates, were performed for 1-5 and (2-carboxyethyl) triphenylphosphonium bromide (TPP) in the dark. Similar assays were performed for 1, 2, 4 and TPPBr under visible light-induced CO release conditions. For all experiments, MTT (Sigma-Aldrich) was prepared fresh at $5 \mathrm{mg} / \mathrm{mL}$ in sterile PBS. MTT assays were performed using HUVEC or A549 cells as described the supporting information with final DMSO concentration of $0.4 \%(\mathrm{v} / \mathrm{v})$. The final results were background subtracted and normalized to vehicle control. Data analysis was performed using GraphPad Prism 7 (La Jolla, California), with values reported as mean \pm SEM. $\mathrm{IC}_{50}$ values were calculated as nonlinear regression with a bottom constraint of zero.

\section{Bioenergetics analysis in cultured cells}

An XF96 Extracellular Flux Analyzer (Agilent Technologies, Santa Clara, CA, USA) at the University of Utah Core Facilities was used to measure mitochondrial bioenergetics in A549 cells. Briefly, the A549 cells were seeded into Seahorse XF96-well plates at a density of 20,000 cells/well $24 \mathrm{~h}$ before the experiment. On the day of the experiment, the cells were incubated with vehicle $(0.4 \%$ DMSO) or $\mathbf{1}, 2$ or $\operatorname{TPPBr}(0.1,1.0,10 \mu \mathrm{M})$ for $4 \mathrm{~h}$. One of the two prepared plates was then subjected to illumination using a blue LED array for $1 \mathrm{~h}$ at $37^{\circ} \mathrm{C}$. The second plate remained in the incubator in the dark for the same amount of time. The culture media in each plate was then replaced with assay medium (Seahorse XF Base Medium supplemented with $1 \mathrm{mM}$ pyruvate, $2 \mathrm{mM}$ glutamine, and $25 \mathrm{mM}$ glucose, adjusted to $\mathrm{pH} 7.4$ with $0.1 \mathrm{~N} \mathrm{NaOH}$ and filtered through a $0.22 \mu \mathrm{m}$ filter). The plates were then incubated at $37{ }^{\circ} \mathrm{C}$ without $\mathrm{CO}_{2}$ for $30 \mathrm{~min}$. Changes in oxygen consumption rate (OCR) were assessed over $80 \mathrm{~min}$ after sequential addition of oligomycin $(1.0 \mu \mathrm{M})$, carbonyl cyanide- $p$-trifluoromethoxyphenylhydrazone (FCCP) $(1.0 \mu \mathrm{M})$ and rotenone/antimycin A $(1.0 \mu \mathrm{M} / 1.0 \mu \mathrm{M})$. The following parameters were determined from OCR measurements: stimulated respiration (the last value of OCR after exposure to vehicle or CO-donor and preceding oligomycin injection); ATP-linked respiration (the difference between OCR before and after oligomycin injection); proton leak (the difference between OCR after oligomycin and rotenone/antimycin A injection); maximal respiration (the difference between OCR after FCCP and rotenone/antimycin A injection); reserve capacity (the difference between OCR after FCCP and stimulated respiration before oligomycin injection); and non-mitochondrial respiration (the OCR value after rotenone/antimycin A injection).$^{28}$ The Seahorse XF results are presented as means \pm SEM from three independent experiments ( 8 technical replicates in each experiment). For statistical analysis, one-way ANOVA was performed for each parameter listed above with Tukey post-hoc test for multiple comparisons among test concentrations. A $p$ value $<0.05$ was considered to be statistically significant. 


\section{Supplementary Material}

Refer to Web version on PubMed Central for supplementary material.

\section{Acknowledgments}

We thank L. Barrow (University of Utah, Department of Pharmacology and Toxicology) for use of laboratory space for cellular preparations for bioenergetics experiments.

\section{Funding Sources}

We thank the National Institutes of Health (R15GM124596 to LMB and ADB), the National Science Foundation (CHE-1429195 for Brüker Avance III HD Ascend-500 spectrometer), the Utah Agricultural Experiment Station (project UTA-01178 to ADB), and the Utah State University Office of Research and Graduate Studies (Research Catalyst grant; PDRF Fellowship to TS) for financial support.

\section{References}

1. Shefa U, Yeo SG, Kim MS, Song IO, Jung J, Jeong NY, Huh Y. Role of gasotransmitters in oxidative stresses, neuroinflammation, and neuronal repair. BioMed Res Int. 2017; 2017:1689341. [PubMed: 28386548]

2. Motterlini R, Foresti R. Biological signaling by carbon monoxide and carbon monoxide-releasing molecules. Am J Physiol Cell Physiol. 2017; 312:C302-C313. [PubMed: 28077358]

3. Queiroga CSF, Vercelli A, Vieira HLA. Carbon monoxide and the CNS: challenges and achievements. Br J Pharmacol. 2015; 172:1533-1545. [PubMed: 24758548]

4. Motterlini R, Otterbein LE. The therapeutic potential of carbon monoxide. Nat Rev Drug Disc. 2010; 9:728-743.

5. Bilban M, Haschemi A, Wegiel B, Chin BY, Wagner O, Otterbein LE. Heme oxygenase and carbon monoxide initiate homeostatic signaling. J Mol Med (Berl). 2008; 86:267-279. [PubMed: 18034222]

6. Weber RE, Vinogradov SN. Nonvertebrate hemoglobins: functions and molecular adaptations. Physiol Rev. 2001; 81:569-628. [PubMed: 11274340]

7. Schallner N, Otterbein LE. Friend or foe? Carbon monoxide and the mitochondria. Front Physiol. 2015; 6:1-4. [PubMed: 25688210]

8. Boczkowski J, Poderoso JJ, Motterlini R. CO-metal interaction: vital signaling from a lethal gas. Trends Biochem Sci. 2006; 31:614-621. [PubMed: 16996273]

9. Romão CC, Vieira HLA. Metal carbonyls for CO-based therapies: challenges and successes. In: Pombeiro AJL, editorAdvances in Organometallic Chemistry and Catalysis. Wiley-Blackwell; 2013. 545-561.

10. Iacono LL, Boczkowski J, Zini R, Salouage I, Berdeaux A, Motterlini R, Morin D. A carbon monoxide-releasing molecule (CORM-3) uncouples mitochondrial respiration and modulates the production of reactive oxygen species. Free Radic Biol Med. 2011; 50:1556-1564. [PubMed: 21382478]

11. Wilson JL, Bouillaud F, Almeida AS, Vieira HL, Ouidja MO, Dubois-Randé JL, Foresti R, Motterlini R. Carbon monoxide reverses the metabolic adaptation of microglia cells to an inflammatory stimulus. Free Radic Biol Med. 2017; 104:311-323. [PubMed: 28108277]

12. Kaczara P, Motterlini R, Rosen GM, Augustynek B, Bednarczyk P, Szewczyk A, Foresti R, Chlopicki S. Carbon monoxide released by CORM-401 uncouples mitochondrial respiration and inhibits glycolysis in endothelial cells: a role for mitoBKCa channels. Biochim Biophys Acta. 2015; 1847:1297-1309. [PubMed: 26185029]

13. Reiter CEN, Alayash AI. Effects of carbon monoxide (CO) delivery by a CO donor or hemoglobin on vascular hypoxia inducible factor $1 a$ and mitochondrial respiration. FEBS Open Bio. 2012; 2:113-118.

14. Chance B, Erecinska M, Wagner M. Mitochondrial responses to carbon monoxide toxicity. Ann NY Acad Sci. 1970; 174:193-204. [PubMed: 4332407] 
15. Queiroga CSF, Almeida AS, Vieira HLA. Carbon monoxide targeting mitochondria. Biochem Res Int. 2012; 2012:749845. [PubMed: 22536507]

16. Anderson SN, Richards JM, Esquer HJ, Benninghoff AD, Berreau LM. A structurally-tunable 3hydroxyflavone motif for visible light-induced carbon monoxide-releasing molecules (CORMs). ChemistryOpen. 2015; 4:590-594. [PubMed: 26491637]

17. Soboleva T, Esquer HJ, Benninghoff AD, Berreau LM. Sense and release: a thiol-responsive flavonol-based photonically driven carbon monoxide-releasing molecule that operates via a multiple-input AND logic gate. J Am Chem Soc. 2017; 139:9435-9438. [PubMed: 28677975]

18. Soboleva T, Benninghoff AD, Berreau LM. An $\mathrm{H}_{2} \mathrm{~S}$-sensing/CO-releasing flavonol that operates via logic gates. ChemPlusChem. 2017; 82:1408-1412.

19. Logan A, Murphy MP. Using chemical biology to assess and modulate mitochondria: progress and challenges. Interface Focus. 2017; 7:20160151. [PubMed: 28382206]

20. Yang K, Kolanowski JL, New EJ. Mitochondrially targeted fluorescent redox sensors. Interface Focus. 2017; 7:20160105. [PubMed: 28382201]

21. Sassi N, Biasutto L, Mattarei A, Carraro M, Giorgio V, Citta A, Bernardi P, Garbisa S, Szabò I, Paradisi C, Zoratti M. Cytotoxicity of a mitochondriotropic quercetin derivative: mechanisms. Biochim Biophys Acta. 2012; 1817:1095-1106. [PubMed: 22433608]

22. Algar J, Flynn JP. A new method of the synthesis of flavonols. Proc Roy Irish Acad. 1934; 42B:18.

23. Oyamada B. A new general method for the synthesis of the derivatives of flavonol. Bull Chem Soc Jpn. 1935; 10:182-186.

24. Ross MF, Kelso GF, Blaikie FH, James AM, Cochemé HM, Filipovska A, Da Ros T, Hurd TR, Smith RA, Murphy MP. Lipophilic triphenylphosphonium cations as tools in mitochondrial bioenergetics and free radical biology. Biochemistry (Mosc). 2005; 70:222-230. [PubMed: 15807662]

25. Murphy MP. Targeting lipophilic cations to mitochondria. Biochim Biophys Acta. 2008; 1777:1028-1031. [PubMed: 18439417]

26. Popova M, Soboleva T, Arif AM, Berreau LM. Properties of a flavonol-based photoCORM in aqueous buffered solutions: influence of metal ions, surfactants and proteins on visible lightinduced CO release. RSC Adv. 2017; 7:21997-22007.

27. Buravkov SV, Pogodina MV, Buravkova LB. Comparison of mitochondrial fluorescent dyes in stromal cells. Bull Exp Biol Med. 2014; 157:654-658. [PubMed: 25257434]

28. Divakaruni AS, Paradyse A, Ferrick DA, Murphy AN, Jastroch M. Analysis and interpretation of microplate-based oxygen consumption and $\mathrm{pH}$ data. In: Murphy AN, Chan DC, editorsMethods in Enzymology. Vol. 547. Elsevier Inc; Kidlington, UK: 2014. 309-354.

29. Carrasco-Pozo C, Tan KN, Reyes-Farias M, De La Jara N, Ngo ST, Garcia-Diaz DF, Llanos P, Cires MJ, Borges K. The deleterious effect of cholesterol and protection by quercetin on mitochondrial bioenergetics of pancreatic $\beta$-cells, glycemic control and inflammation: in vitro and in vivo studies. Redox Biol. 2016; 9:229-243. [PubMed: 27591402]

30. Sharma DR, Sunkaria A, Wani WY, Sharma RK, Verma D, Priyanka K, Bal A, Gill KD. Quercetin protects against aluminum induced oxidative stress and promotes mitochondrial biogenesis via activation of the PGC-1a signaling pathway. Neurotoxicology. 2015; 51:116-137. [PubMed: 26493151]

31. Zholobenko AV, Mouithys-Mickalad A, Dostal Z, Serteyn D, Modriansky M. On the causes and consequences of the uncoupler-like effects of quercetin and dehydrosilybin in H9c2 cells. PLoS One. 2017; 12:e0185691. [PubMed: 28977033]

32. Pazin M, Andreo TB, Pereira LC, Bernardes MFF, Ferrari RS, Dorta DJ. Baicalein can be a great antioxidant, but it can impair mitochondrial bioenergetics and cause cytotoxicity at high concentrations. Applied Research in Toxicology. 2015; 1:9-18.

33. Babu D, Leclercq G, Motterlini R, Lefebvre RA. Differential effects of CORM-2 and CORM-401 in murine intestinal epithelial MODE-K cells under oxidative stress. Front Pharmacol. 2017; doi: 10.3389/fphar.2017.00031 
34. Ramáo CC, Vieira HLA. Metal Carbonyl Prodrugs: CO Delivery and Beyond. In: Jaouen G, Salmain M, editorsBioorganometallic Chemistry: Applications in Drug Discovery, Biocatalysis, and Imaging. Wiley-VCH; Weinheim, Germany: 2015. 175-176.

35. Follit CA, Woodruff SR, Vogel PD, Wise JG, Tsarevsky NV. Cationic branched polymers for cellular delivery of negatively charged cargo. J Drug Deliv Sci Technol. 2017; 39:324-333. [PubMed: 29503667]

36. Zheng Y, Ji X, Yu B, Yi K, Gallo D, Csizmadia E, Zhu M, Choudhury MR, De La Cruz LKC, Chittavong V, Pan Z, Yuan Z, Otterbein LE, Wang B. Enrichment-triggered prodrug activation demonstrated through mitochondria-targeted delivery of doxorubicin and carbon monoxide. Nat Chem. 2018; doi: 10.1038/s41557-018-0055-2

37. Antony LAP, Slanina T, Sebej P, Solomek T, Klán P. Fluorescein analogue xanthene-9-carboxylic acid: A fransition-metal-free CO releasing molecule activated by green light. Org Lett. 2013; 15:4552-4555. [PubMed: 23957602]

38. Palao E, Slanina T, Muchová L, Solomek T, Vitek L, Klán P. A transition-metal-free CO-releasing BODIPY derivatives activatable by visible to NIR light as promising bioactive molecules. J Am Chem Soc. 2016; 138:126-133. [PubMed: 26697725]

39. Peng P, Wang C, Shi Z, Johns VK, Ma L, Oyer J, Copik A, Igarashi R, Liao Y. Visible-light activatable organic CO-releasing molecules (photoCORMs) that simultaneously generate fluorophores. Org Biomol Chem. 2013; 11:6671-6674. [PubMed: 23943038]

40. Grubel K, Saraf SL, Anderson SN, Laughlin BJ, Smith RC, Arif AM, Berreau LM. Synthesis, characterization, and photoinduced $\mathrm{CO}$-release reactivity of a $\mathrm{Pb}(\mathrm{II})$ flavonolate complex: comparisons to group 12 analogs. Inorg Chim Acta. 2013; 407:91-97.

41. Hatchard CG, Parker CA. A new sensitive chemical actinometer - II. Potassium ferrioxalate as a standard chemical actinometer. Proc R Soc Lond A. 1956; 235:518-536.

42. Kuhn HJ, Braslavsky SE, Schmidt R. Chemical actinometry. Pure Appl Chem. 2004; 76:21052146.

43. Wei-Li D, Bi J, Sheng-Lian L, Xu-Biao L, Xin-Man T, Chak-Tong A. Functionalized phosphonium-based ionic liquids as efficient catalysts for the synthesis of cyclic carbonate from epoxides and carbon dioxide. Appl Catal, A. 2014; 470:183-188.

44. Reddy MK, Varathan E, Lobo NP, Roy A, Narasimhaswamy T, Ramanathan KV. Monolayer to interdigitated partial bilayer smectic $\mathrm{c}$ transition in thiophene-based spacer mesogens: X-ray diffraction and ${ }^{13} \mathrm{C}$ nuclear magnetic resonance studies. Langmuir. 2015; 31:10831-10842. [PubMed: 26366989]

45. Fletcher DI, Ganellin CR, Piergentili A, Dunn PM, Jenkinson DH. Synthesis and pharmacological testing of polyaminoquinolines as blockers of the apamin-sensitive $\mathrm{Ca}^{2+}$-activated $\mathrm{K}^{+}$channel (SK $\mathrm{Ca}_{\text {a }}$. Bioorg Med Chem. 2007; 15:5457-5479. [PubMed: 17560109]

46. Rahman SMA, Baba T, Kodama T, Islam MdA, Obika S. Hybridizing ability and nuclease resistance profile of backbone modified cationic phosphorothioate oligonucleotides. Bioorg Med Chem. 2012; 20:4098-4102. [PubMed: 22658536] 

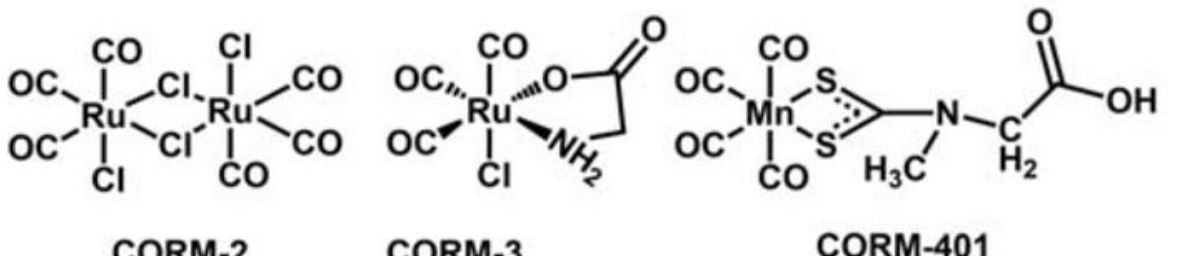

CORM-2

CORM-3

CORM-401

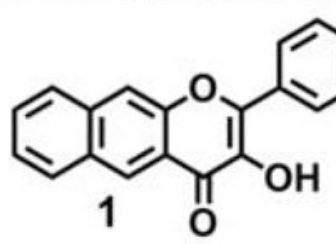

Figure 1.

Carbon monoxide releasing molecules (CORMs) previously used in mitochondria bioenergetics studies (top) and the framework of photoCORMs described in this work (bottom). 
(a)

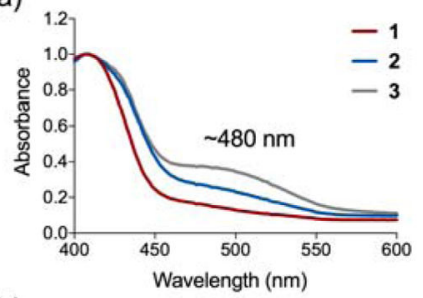

(b)

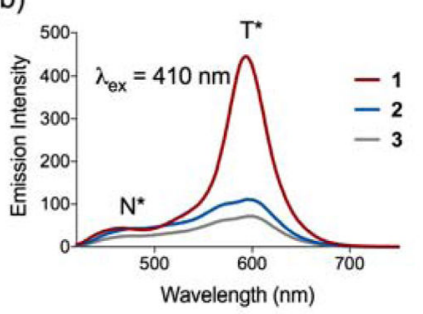

(c)

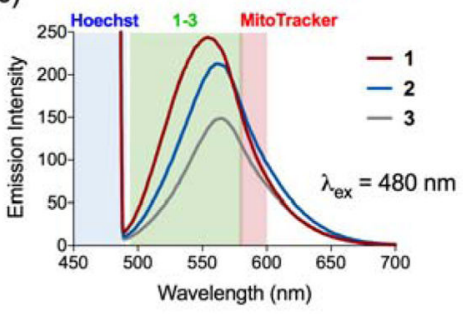

Figure 2.

Absorption (a) and emission spectra (b,c) of 1-3 in media containing 10\% FBS at $100 \mu \mathrm{M}$. Blue, green and red coloration of spectral sections in (c) indicate the confocal detection ranges. 

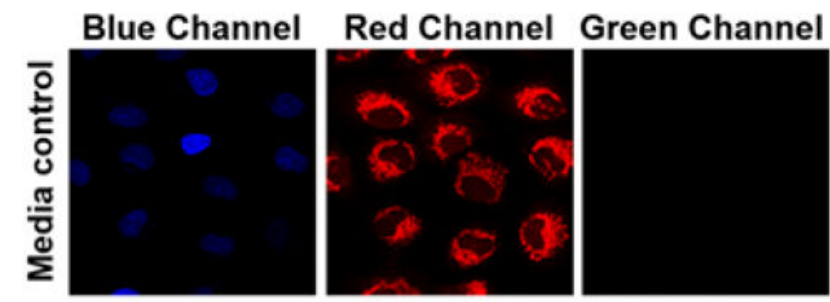

Merged
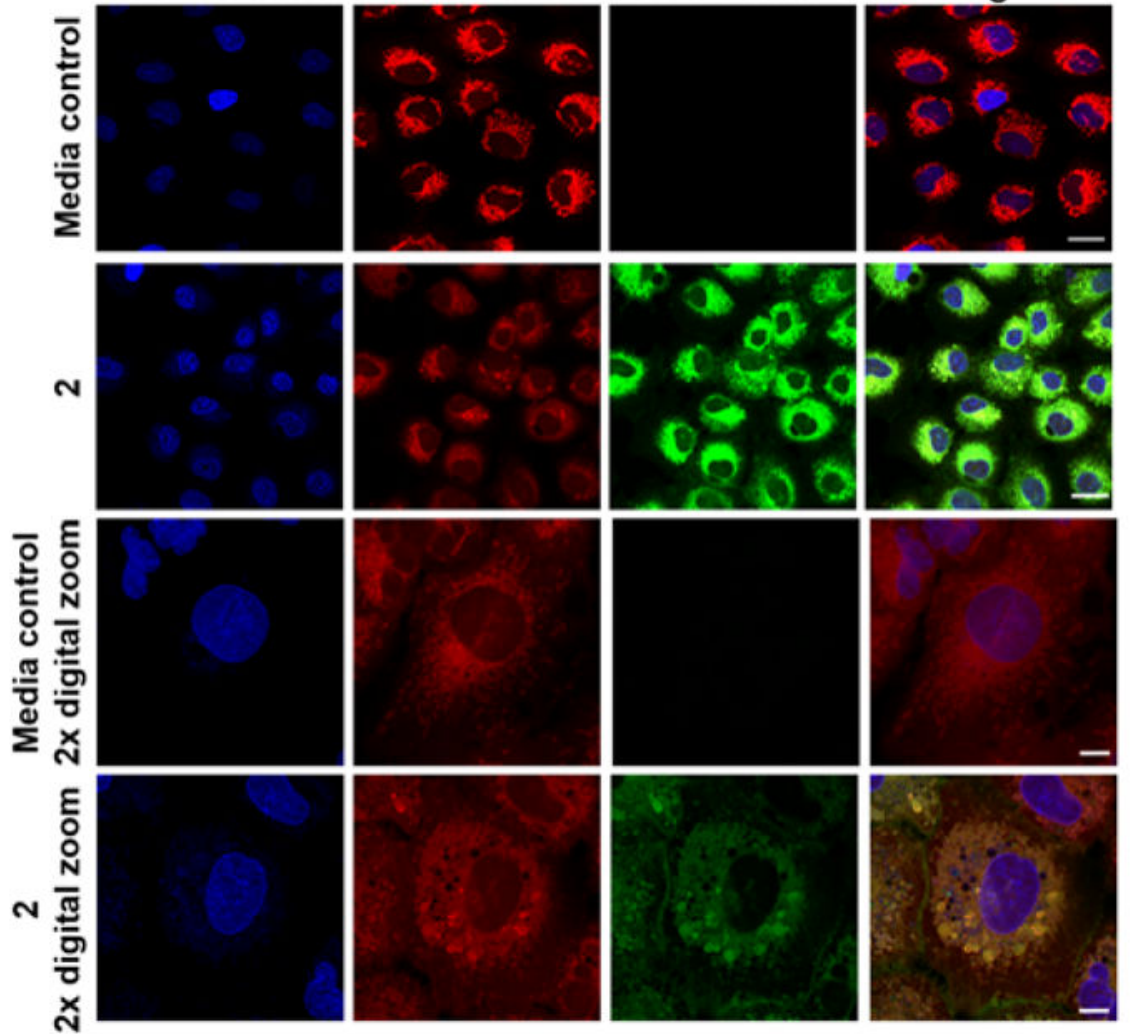

Figure 3.

Confocal microscopy images showing co-localization of 2 with MTR in A549 cells. Rows 1 and 3 show cells treated with vehicle control (0.4\% DMSO). Rows 2 and 4 show cells treated with 2 at $100 \mu \mathrm{M}$ for $4 \mathrm{~h}$. Image panels depict the Hoechst nuclear stain ( blue), the MitoTracker mitochondria stain ( red) the $\mathrm{CO}$ donor ( green ) or a merge of the three fluorescence channels. Scale bar indicates $20 \mu \mathrm{m}$ for rows 1 and 2 . Scale bar indicates $10 \mu \mathrm{m}$ for rows 3 and 4 . 
(a)

(b)

Figure 4.
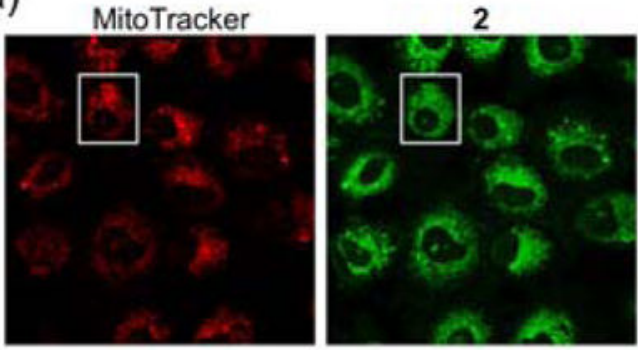

Co-localized pixels
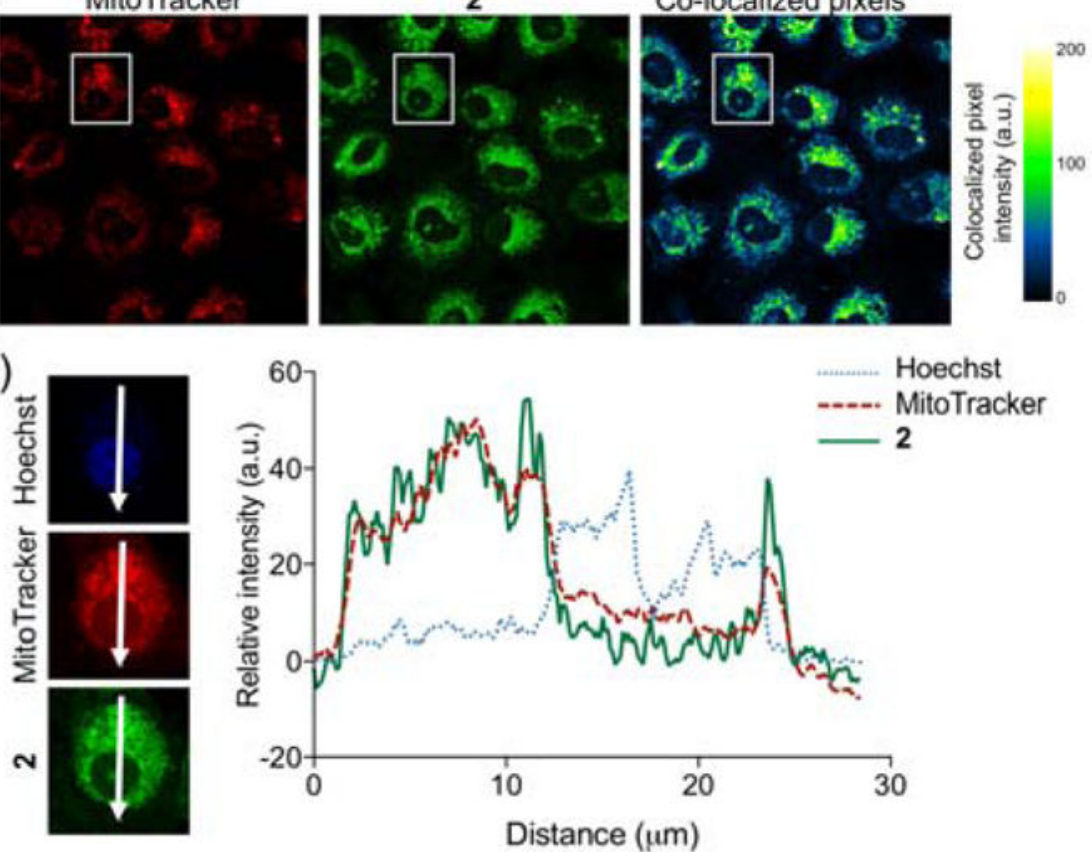

Hoechst MitoTracker 2

Confocal images of A549 cells co-stained with 2, MTR and Hoechst 33342. (a) Independent and co-localized pixels of $\mathbf{2}$ and MTR. (b) Overlaid intensity profile of regions of interest (ROIs) in the co-stained A549 cells as indicated by the white arrows. 

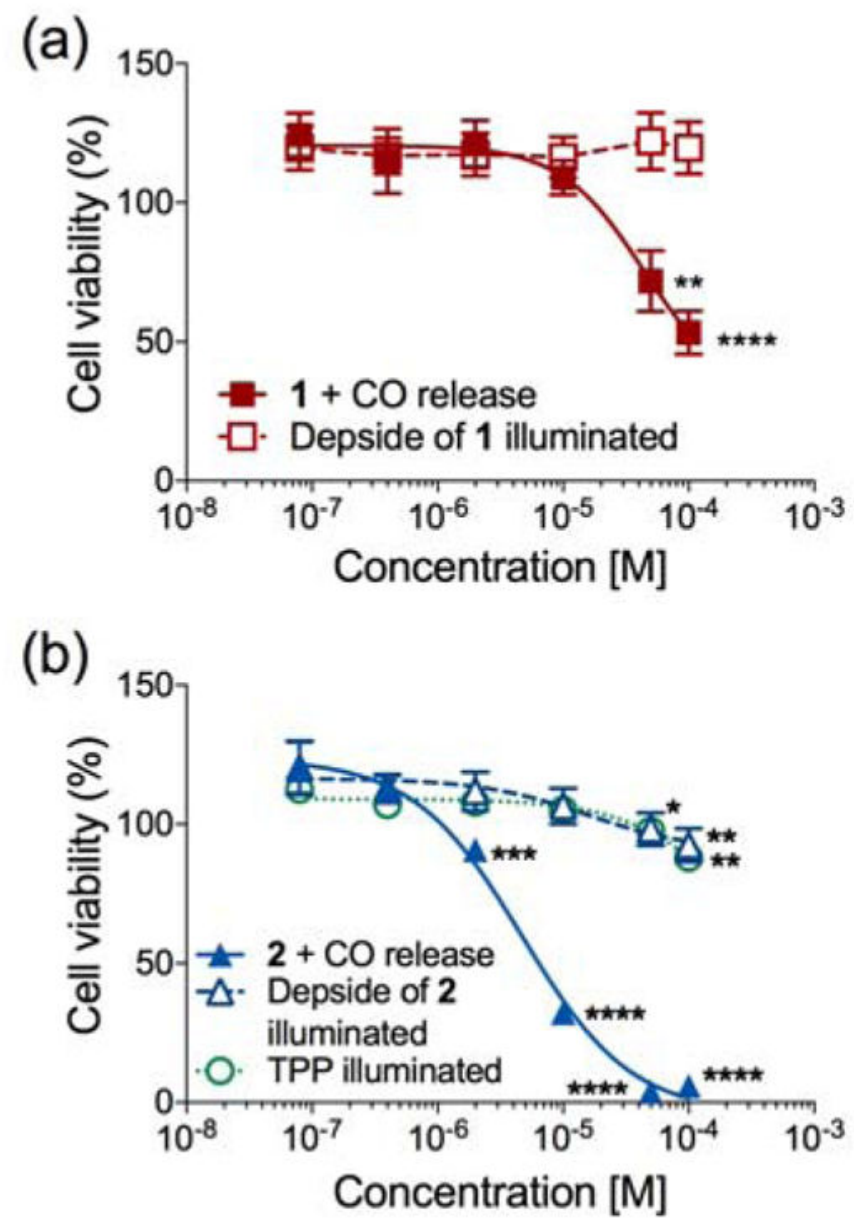

Figure 5.

Plots of percent cell viability in A549 cells for 1 (a), or $\mathbf{2}$ (b), their photo-induced reaction products, and 2-carboxyethyl-triphenylphosphonium bromide upon illumination in cells. 
(a) No illumination
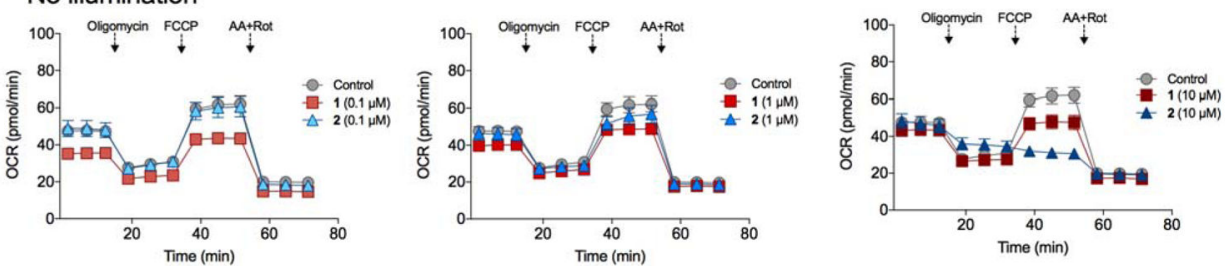

(b) Illuminated
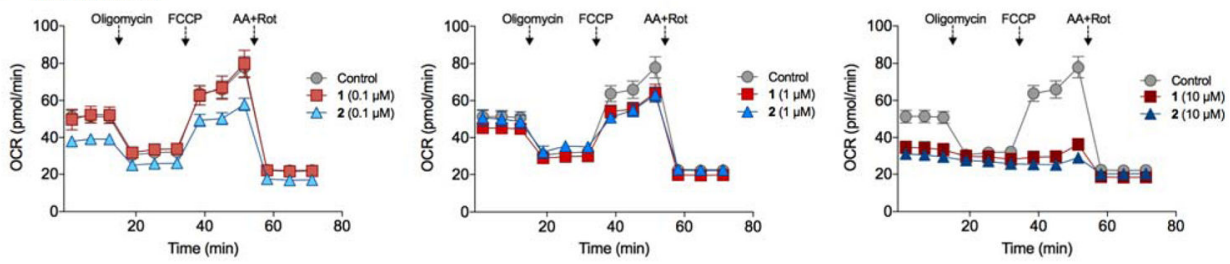

(c) Illuminated
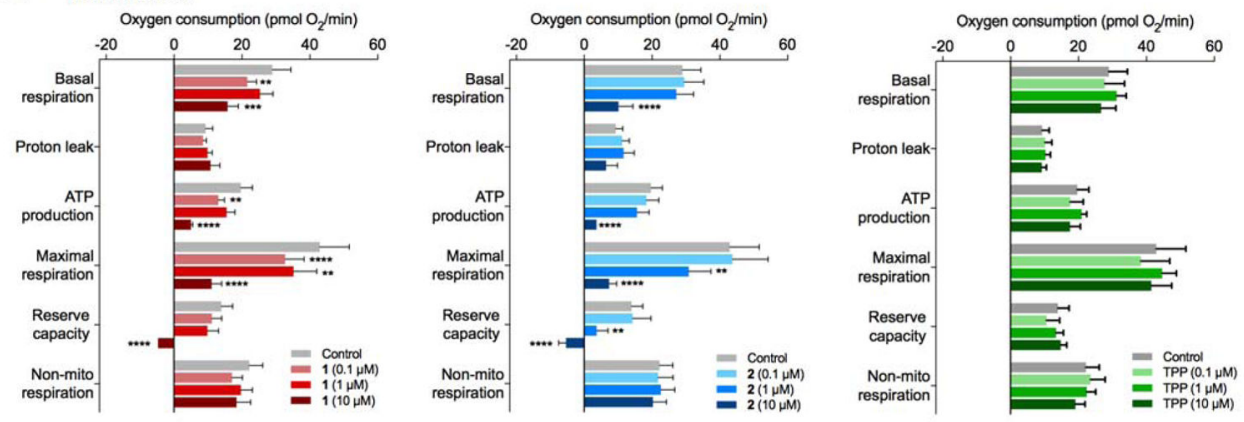

Figure 6.

Cellular bioenergetics analysis in A549 cells. (a) OCR profiles of cells without lighttriggered $\mathrm{CO}$ release. (b) OCR profiles of cells after $1 \mathrm{~h}$ illumination to trigger $\mathrm{CO}$ release in situ. (c) Bioenergetics data of illuminated cells ( $1 \mathrm{~h}$ post $\mathrm{CO}$ release) including basal respiration, proton leak, ATP production, maximal respiration, reserve capacity, and nonmitochondrial respiration in the presence of $\mathbf{1}$ (red), $\mathbf{2}$ (blue) and TPP tail (green) at the 0.1$10 \mu \mathrm{M}$ concentration range. Abbreviations: FCCP, carbonyl cyanide 4(trifluoromethoxy)phenylhydrazone; AA+Rot, antimycin A and rotenone. Values represent the means \pm SEMs from three independent biological experiments. The values that are significantly different compared to control by one-way ANOVA test are indicated by asterisks as follows: ${ }^{*} \mathrm{p}<0.05, * * \mathrm{p}<0.01, * * * \mathrm{p}<0.001, * * * * \mathrm{p}<0.0001$. 

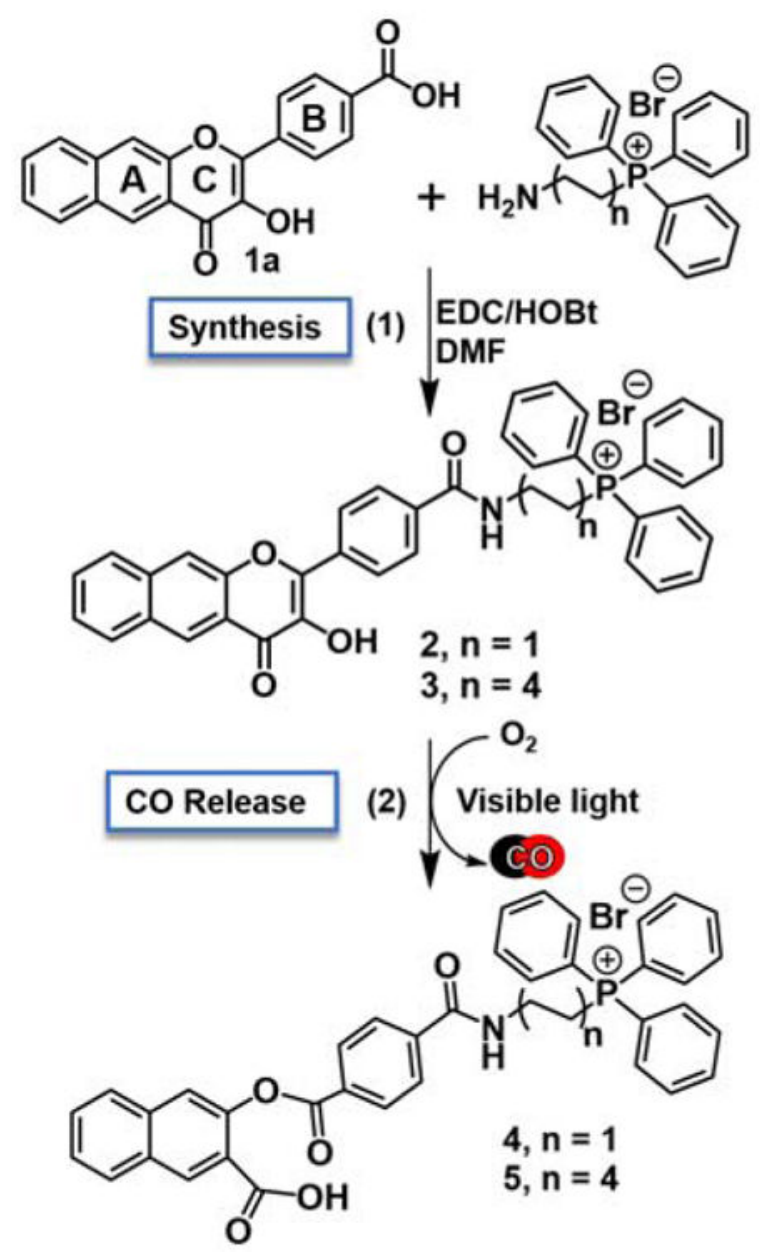

Scheme 1.

(1) Preparation of mitochondrial-targeting photoCORMs 2 and $\mathbf{3}$ via EDC/HOBt coupling between 1a and the TPP tail. (2) Visible light-induced CO release reactivity of $\mathbf{2}$ and $\mathbf{3}$ to generate $\mathbf{4}$ and $\mathbf{5}$, which are non-fluorescent molecules. 